\title{
Canadian credentialing guidelines for flexible sigmoidoscopy
}

\author{
Robert Enns MD FRCPC ${ }^{1}$, Joseph Romagnuolo MD FRCPC FASGE MScEpid ${ }^{2}$, Terry Ponich MD FRCPC ${ }^{3}$, \\ Jonathon Springer MD FRCPC ${ }^{4}$, David Armstrong MA MB BChir FRCPC FRCP(UK) AGAF FACG ${ }^{5}$, \\ Alan N Barkun MD CM MSc FRCPC 6
}

A series of credentialing guidelines for gastrointestinal endoscopic procedures has been developed by the Canadian Association of Gastroenterology (CAG) Endoscopy Committee. The guidelines were reviewed and approved by the Clinical Affairs Committee, and endorsed by the Executive Board. In the present article, the CAG suggests specific guidelines for credentialing flexible sigmoidoscopy. It is intended to be read in conjunction with the introductory article that outlines the principles of credentialing (1).

The CAG does not credential individuals for endoscopic procedures; that is the responsibility of the endoscopist's local institution or facility. The purpose of these guidelines is to provide a framework that will allow organizations to assess the training and competence of applicants to perform colonoscopy, as part of the credentialing process for the granting of privileges.

Flexible sigmoidoscopy allows direct visualization of the colonic mucosa, from the rectum to

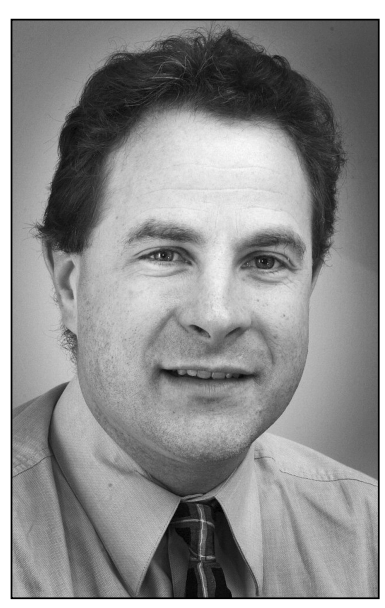

Dr Robert Enns
A clear understanding of indications and alternative investigations is critical to the performance of any invasive procedure. Although complications are very rare, a review of any 'sentinel event' (an unexpected occurrence involving death or serious physical or psychological injury, or the risk thereof) (8) will, by necessity, evaluate the indication for the procedure in assessing the patient's overall management.

\section{Documentation}

Training in adequate documentation is necessary, because the findings at flexible sigmoidoscopy may lead to referral for colonoscopy; the ability to accurately record the size, appearance, number and location of any lesions is, therefore, an essential component of flexible sigmoidoscopy.

\section{TECHNICAL ASPECTS}

Technical skills

Minimum number of procedures: The number Although colonoscopy has become a preferred method for colon cancer screening, it may not always be available, and flexible sigmoidoscopy every five years has been endorsed as an acceptable screening option (2-5).

\section{COGNITIVE ASPECTS}

The technical skills required to perform flexible sigmoidoscopy safely and effectively must be accompanied by a full understanding of the cognitive aspects of the procedure (Table 1). These cognitive aspects should be fully addressed in the training of anyone who will be performing flexible sigmoidoscopy (6).

\section{Appropriate indications}

Flexible sigmoidoscopy can be performed for many reasons; the most common are listed in Table 2 (7). The advantages of flexible sigmoidoscopy are that it can be performed as an outpatient procedure with minimal preparation, without sedation and without significant patient discomfort, in a few minutes. of procedures completed during training is currently the only objective measure available to assess competence, and subsequently, to evaluate maintenance of competence to practise sigmoidoscopy. While other measures, such as depth of insertion, important, there are no objective mechanisms to assess these parameters. The American Society for Gastrointestinal Endoscopy (ASGE) recommends the completion of at least 30 flexible sigmoidoscopies as the threshold number of procedures that must be performed before competency can be assessed (9). This requirement is slightly more stringent than those of the Society of Gastrointestinal Nurses and Associates in the United States, and the Society of American Gastrointestinal Endoscopic Surgeons, both of which recommend 25 supervised procedures $(10,11)$.

The flexible sigmoidoscopy training program, developed by the ASGE for the core curriculum, proposes initial supervised training using a model, followed by five supervised withdrawals of the sigmoidoscope on patients, and then, 20 procedures detection of polyps and cancer, and complication rates, are

${ }^{1}$ Division of Gastroenterology, University of British Columbia, Vancouver, British Columbia; ${ }^{2}$ Division of Gastroenterology and Hepatology,

Departments of Medicine and Biostatistics, Bioinformatics, and Epidemiology, Medical University of South Carolina, Charleston, South

Carolina, USA; ${ }^{3}$ Division of Gastroenterology, University of Western Ontario, London; ${ }^{4}$ St Joseph's Health Centre, Toronto; ${ }^{5}$ Division of

Gastroenterology, McMaster University, Hamilton, Ontario; ${ }^{6}$ Division of Gastroenterology, McGill University, Montreal, Quebec

Correspondence: Dr David Armstrong, Division of Gastroenterology, Health Sciences Centre 2F55, McMaster University Medical Centre,

1200 Main Street West, Hamilton, Ontario L8N 325. Telephone 905-521-2100 ext 76404, fax 905-523-6048, e-mail armstro@mcmaster.ca

Received for publication September 6, 2007. Accepted September 7, 2007 


\section{TABLE 1}

\section{Cognitive aspects of flexible sigmoidoscopy}

Safe and effective flexible sigmoidoscopy requires a full understanding of:

- Indications for flexible sigmoidoscopy;

- Contraindications to and limitations of flexible sigmoidoscopy;

- The principles of informed consent;

- The anatomy of the anorectum and the sigmoid and descending colon;

- The principles of conscious sedation;

- Indications for and contraindications of mucosal biopsy during flexible sigmoidoscopy;

- Indications for and contraindications to polypectomy during flexible sigmoidoscopy;

- The principles of endoscopic reporting and documentation;

- The initial management of the patient postprocedure;

- The recognition and management of potential complications; and

- Appropriate referral for complications, an incomplete procedure or abnormal findings

under direct supervision of credentialed physician endoscopists, including three biopsies under direct supervision and documentation of consistent sigmoidoscope insertion to a depth of more than $50 \mathrm{~cm}$. Thereafter, the trainee should perform an additional 25 complete procedures, with a physician preceptor readily available (12).

There are few objective data to support the requirement that trainees should perform 25 or 30 unassisted procedures before they can be deemed competent at flexible sigmoidoscopy. A study by Hawes et al (13) assessed 494 flexible sigmoidoscopic examinations after recording insertion distance, withdrawal time, quadrants viewed on withdrawal, number of correctly diagnosed lesions and management scores. More than 24 to 30 procedures were deemed necessary to train the resident adequately; at that stage, the residents detected $93 \%$ to $100 \%$ of polyps and cancers noted by experienced endoscopists. However, with further experience, unassisted insertion distance and luminal visualization increased, while insertion time and assisted time decreased.

The ASGE core curriculum also proposes an ongoing evaluation program to document performance of a minimum of 50 procedures per year, consistent insertion of the sigmoidoscope to a depth of more than $50 \mathrm{~cm}$ and performance of five biopsies per year (12).

Depth of insertion: Specific technical requirements for flexible sigmoidoscopy include identification of the splenic flexure (although the splenic flexure is not reached in many sigmoidoscopies) and retroflexion within the rectum for all cases (14).

Although the extent of examination of the distal colon may be affected by the use, in some instances, of an upper endoscope or a colonoscope, the expected depth of insertion, which is discussed below, refers to the use of a standard flexible sigmoidoscope. The definition of an adequately inserted screening flexible sigmoidoscope is subjective and not currently defined. However, in principle, it should be possible to insert the entire length of the flexible sigmoidoscope, provided that it does not cause undue patient discomfort. In practice, one should examine as much of the distal colon as possible, recognizing that it can be difficult to precisely define the furthest extent of the colon that has been examined (6). It is
TABLE 2

Common indications for flexible sigmoidoscopy

- Suspected left colonic disease, distal to the splenic flexure, in a young patient

- Assessment of known distal colitis

- Surveillance of an anastomosis after resection of a distal colon cancer

- Surveillance of the rectal remnant after subtotal colectomy and reanastomosis for colitis

- Screening for colon cancer in:

- Average-risk individuals; and

- Individuals with suspected familial adenomatous polyposis

Adapted from reference 7

expected that the rectum and sigmoid colon should be inspected completely and the descending and more proximal colon can often also be visualized. For colon cancer screening, the goal is to examine as much of the distal colon as possible, based on the length of the endoscope (usually $60 \mathrm{~cm}$ to $70 \mathrm{~cm}$ ) and patient tolerance.

The adequacy of the visualization may vary depending on the preparation used. The preparation should be such that the endoscopist is confident that lesions other than small polyps (5 mm or smaller) were not obscured (6).

In general, flexible sigmoidoscopy is associated with high levels of patient satisfaction $(15,16)$. Patients should not experience undue discomfort and, because flexible sigmoidoscopy is usually performed without sedation, patient comfort should not be compromised by attempting to examine as much of the distal colon as possible. Variations in patient tolerance and anatomical factors, such as angulation and tortuosity of the sigmoid colon and prior surgery may, on occasion, be associated with discomfort, requiring the use of mild sedation; they may also limit insertion depth.

\section{Success rates}

Adenoma detection and referral for colonoscopy: The proportion of sigmoidoscopies resulting in referral for colonoscopy should be similar for all endoscopists; this referral rate is partly dependent on the endoscopist's polyp detection rate and partly on an appropriate referral strategy (16). Patients who have only hyperplastic polyps in the distal colon do not require colonoscopy. Colonoscopy is indicated if one or more adenomata are found, regardless of their size. If a large polyp (larger than $1 \mathrm{~cm}$ ) is found at flexible sigmoidoscopy, colonoscopy is indicated to completely remove the lesion and exclude proximal neoplasia (6).

Therapeutic interventions: The most common therapeutic interventions at flexible sigmoidoscopy are biopsy and polypectomy. All endoscopists performing flexible sigmoidoscopy should be able to acquire accurately targeted biopsies. The removal of smaller polyps (smaller than $1 \mathrm{~cm}$ ) at flexible sigmoidoscopy requires that the sigmoidoscopist be trained in the techniques of cold biopsy or snaring. Polypectomy, with removal of polyps larger than $1 \mathrm{~cm}$ in diameter, is not usually performed at sigmoidoscopy; this is, in part, because the remainder of the colon will need to be examined for synchronous lesions. The removal of larger polyps (larger than $1 \mathrm{~cm}$ ) requires an endoscopist with adequate training, in addition to appropriate colonic preparation. Unless carbon dioxide has been used for colonic insufflation, full colonic preparation is required before cautery to minimize the rare risk of thermal 
injury from flammable gases that may be present in an inadequately prepared colon.

\section{Complication rates}

Complications, such as bleeding and perforation, are very rare, being reported at a rate of one in 25,000 to 50,000 flexible sigmoidoscopies (16-18). The risk of bleeding after polypectomy is also low, with an expected rate of major postpolypectomy bleeding of less than 1\% (19-23); however, significant bleeding is very uncommon (16). Other complications (syncope, hypotension and arrhythmia) can also occur, but are very uncommon.

The small, but important risk of explosion and thermal injury associated with the use of electrocautery, hot biopsy forceps or monopolar electrocautery snares in air-insufflated patients can be avoided if carbon dioxide is used to insufflate the colon or if these techniques are eschewed in patients who have not taken an appropriate preparation (24-29).

\section{TRAINING}

Prospective studies are limited as to the most appropriate method to train clinicians to perform screening flexible sigmoidoscopy (30). The cognitive aspect of training should impart a knowledge of basic anatomy, typical pathological findings in the distal colon and rectum, common disease conditions, and the indications and contraindications for flexible sigmoidoscopy, sufficient for the practitioner to perform the procedure safely and accurately. The technical aspect of training should impart the visuomotor skills needed to achieve a full, unassisted examination of the left colon, including a retroflexed view in the rectum (14) and the ability to take targeted, 'cold' biopsies (31) in a safe and efficient manner. It has been shown that technical aspects, including insertion distance, insertion time and luminal visualization, as well as cognitive aspects, including correct diagnosis and management plan formulation, improve with the performance of 25 to 30 procedures (13). However, the study does not indicate the degree of improvement that can be achieved with greater experience or the number of procedures that need to be performed to achieve a predefined or standardized level of competence.

\section{Short courses or simulators}

Short instruction courses in flexible sigmoidoscopy may serve as a starting point in the training process but they do not substitute for supervised training by a competent endoscopy instructor (32). A virtual reality (VR) sigmoidoscopy training system was shown to differentiate among different levels of competence for novice, intermediate and expert endoscopists (33); novice endoscopists were slower and had a shorter insertion length. However, the use of the simulator for training was not assessed in the study. In another study (34), VR simulators were less effective than traditional hands-on training. Residents who received VR training had more difficulty with initial endoscope insertion. The splenic flexure was reached independently in only $29 \%$ of examinations after VR training, compared with $72 \%$ of examinations after hands-on training. Retroflexion was successfully performed by $56 \%$ and $84 \%$ of VR and hands-on trainees, respectively. However, although simulators may not be an adequate substitute for normal training techniques, they may still have a role as an adjunctive training tool, perhaps best used early on in training.

\section{NONPHYSICIANS, NONENDOSCOPIST PHYSICIANS AND FLEXIBLE SIGMOIDOSCOPY}

Flexible sigmoidoscopies have been performed by many different types of health care professionals, including nurses, physician assistants, nonendoscopist physicians, surgeons and gastroenterologists $(6,35,36)$; the term 'nonendoscopist physician' refers to physicians (such as primary care physicians and internists) who have not undergone formal endoscopy training in the context of a specialty gastroenterology or surgery residency program. This is, in part, because sigmoidoscopy is less technically demanding than other endoscopic procedures with a reduced need for sedation and, in part, because of its potential for widespread use as a screening tool.

The adoption of flexible sigmoidoscopy as an acceptable screening option for colon cancer (2-4) would lead to a massive increase in demand for the procedure, even if there were age restrictions for eligible patients or limitations to the frequency of investigation (24). If flexible sigmoidoscopy for colorectal cancer screening were adopted widely, there would be too few gastroenterologists or general surgeon endoscopists to meet the demand. However, it appears that nonphysicians, paramedical staff and nonendoscopist physicians can readily acquire the necessary skills without the need to become fully trained endoscopists (16). In several studies (17,37-42), quality indicators such as average depth of insertion, polyp yield, complications, procedure time and patient satisfaction were all similar for nonphysicians, nongastroenterologist physicians and gastroenterologists. One study (41), involving five gastrointestinal nurses and five residents, reported that four nurses and all residents were competent (as assessed by preset criteria) after 20 procedures, although one nurse did not achieve proficiency after 35 cases, demonstrating variability in learning curves.

\section{SUMMARY}

Technical competence for flexible sigmoidoscopy should be assessed after the completion of at least 25 observed procedures and 30 unassisted procedures; however, completion of this number of procedures does not imply competence (12).

A competent sigmoidoscopist should be able to identify the splenic flexure (even though the splenic flexure is not reached in many sigmoidoscopies) and obtain retroflexion views within the rectum (14). The depth of insertion will vary depending on the patient's anatomy, prior surgery (43), the presence or absence of disease and patient tolerance, but generally, the rectum and sigmoid should be completely evaluated and often, the descending and more proximal colon can also be visualized. A competent sigmoidoscopist should be proficient in performing endoscopic biopsies.

For the practising, credentialed sigmoidoscopist, rates of disease or lesion detection, and rates of referral for colonoscopy should be comparable with those of other competent endoscopists in the institution. Because therapeutic interventions are often undertaken at a subsequent colonoscopy, the findings at flexible sigmoidoscopy must be well documented. Polypectomy rates, for small polyps (smaller than $1 \mathrm{~cm}$ ), should be comparable with those reported by other sigmoidoscopists.

Because complications are very rare, any complication merits serious investigation, and the occurrence of two or more complications in one person's sigmoidoscopy practice may prompt a review of competence, with the possibility that remedial training may be required. 
Training should impart technical skills as well as sufficient knowledge to satisfy the intellectual requirements for flexible sigmoidoscopy, including basic anatomy, typical pathological findings in the distal colon and rectum, and the indications and contraindications for the procedure. Short courses and virtual reality simulators are not substitutes for supervised training by a competent endoscopist.

Institutions that grant privileges for flexible sigmoidoscopy should be encouraged to develop endoscopic reporting mechanisms and databases that will allow clinicians to monitor the quality of their practice and effect improvements if they identify deficiencies, thus maintaining procedural competence and optimizing clinical care over the long term.

ACKNOWLEDGEMENTS: This manuscript was produced with the invaluable assistance of Pauline Lavigne, and the members of the Endoscopy Committee and Clinical Affairs Committee of the Canadian Association of Gastroenterology. At the time of submission, David Armstrong was head of the Endoscopy Committee and Alan Barkun was Chair of the Clinical Affairs Committee for the Canadian Association of Gastroenterology. The project was initiated and initial drafts were written by the Endoscopy Committee under past head, Dr Robert Enns.

\section{REFERENCES}

1. Armstrong D, Enns R, Ponich T, Romagnuolo J, Springer J, Barkun AN. Canadian credentialing guidelines for endoscopic privileges: An overview. Can J Gastroenterol 2007;21:797-801.

2. Smith RA, von Eschenbach AC, Wender R, et al, for the ACS Prostate Cancer Advisory Committee, ACS Colorectal Cancer Advisory Committee, ACS Endometrial Cancer Advisory Committe. American Cancer Society guidelines for the early detection of cancer: Update of early detection guidelines for prostate, colorectal, and endometrial cancers. Also: Update 2001 - testing for early lung cancer detection. CA Cancer J Clin 2001;51:38-75. (Erratum in 2001;51:150).

3. Winawer S, Fletcher R, Rex D, et al, for the Gastrointestinal Consortium Panel. Colorectal cancer screening and surveillance: Clinical guidelines and rationale - Update based on new evidence. Gastroenterology 2003;124:544-60.

4. U.S. Preventive Services Task Force. Screening for colorectal cancer: Recommendation and rationale. Ann Intern Med 2002;137:129-31.

5. Davila RE, Rajan E, Baron TH, et al, for the Standards of Practice Committee, American Society for Gastrointestinal Endoscopy. ASGE guideline: Colorectal cancer screening and surveillance. Gastrointest Endosc 2006;63:546-57. (Erratum in 2006;63:892).

6. Levin TR, Farraye FA, Schoen RE, et al. Quality in the technical performance of screening flexible sigmoidoscopy: Recommendations of an international multi-society task group. Gut 2005;54:807-13.

7. Appropriate use of gastrointestinal endoscopy. American Society of Gastrointestinal Endoscopy. Gastrointest Endosc 2000;52:831-7.

8. The Joint Commission. Sentinel event glossary of terms. <http://www.jointcommission.org/SentinelEvents/se_glossary.htm> (Version current at December 14, 2007).

9. Eisen GM, Baron TH, Dominitz JA, et al, for the American Society for Gastrointestinal Endoscopy. Methods of granting hospital privileges to perform gastrointestinal endoscopy. Gastrointest Endosc 2002;55:780-3.

10. Wexner SD, Eisen GM, Simmang C. Principles of privileging and credentialing for endoscopy and colonoscopy. Surg Endosc 2002;16:367-9.

11. Performance of flexible sigmoidoscopy by registered nurses for the purpose of colorectal cancer screening. SGNA guideline. Society of Gastroenterology Nurses and Associates. Gastroenterol Nurs 2000;23:83-5.
12. ASGE Committee on Training. Flexible sigmoidoscopy for colorectal cancer: Core Curriculum - June 1999. $<$ http://www.asge.org/TrainingEducationIndex.aspx?id=502> (Version current at December 14, 2007).

13. Hawes R, Lehman GA, Hast J, et al. Training resident physicians in fiberoptic sigmoidoscopy. How many supervised examinations are required to achieve competence? Am J Med 1986;80:465-70.

14. Hanson JM, Atkin WS, Cunliffe WJ, et al. Rectal retroflexion: An essential part of lower gastrointestinal endoscopic examination. Dis Colon Rectum 2001;44:1706-8.

15. Schoen RE, Weissfeld JL, Bowen NJ, Switzer G, Baum A. Patient satisfaction with screening flexible sigmoidoscopy. Arch Intern Med 2000;160:1790-6.

16. UK Flexible Sigmoidoscopy Screening Trial Investigators. Single flexible sigmoidoscopy screening to prevent colorectal cancer: Baseline findings of a UK multicentre randomised trial. Lancet 2002;359:1291-300.

17. Levin TR, Conell C, Shapiro JA, Chazen SG, Nadel MR, Selby JV. Complications of screening flexible sigmoidoscopy. Gastroenterology 2002;123:1786-92.

18. Anderson ML, Pasha TM, Leighton JA. Endoscopic perforation of the colon: Lessons from a 10-year study. Am J Gastroenterol 2000;95:3418-22.

19. Silvis SE, Nebel O, Rogers G, Sugawa C, Mandelstam P. Endoscopic complications. Results of the 1974 American Society for Gastrointestinal Endoscopy Survey. JAMA 1976;235:928-30.

20. Nivatvongs S. Complications in colonoscopic polypectomy. An experience with 1555 polypectomies. Dis Colon Rectum 1986;29:825-30.

21. Fruhmorgen P, Demling L. Complications of diagnostic and therapeutic colonoscopy in the Federal Republic of Germany. Results of an inquiry. Endoscopy 1979;11:146-50.

22. Zubarik R, Fleischer DE, Mastropietro C, et al. Prospective analysis of complications 30 days after outpatient colonoscopy. Gastrointest Endosc 1999;50:322-8.

23. Sorbi D, Norton I, Conio M, Balm R, Zinsmeister A, Gostout CJ. Postpolypectomy lower GI bleeding: Descriptive analysis. Gastrointest Endosc 2000;51:690-6.

24 Atkin WS, Edwards R, Wardle J, et al. Design of a multicentre randomised trial to evaluate flexible sigmoidoscopy in colorectal cancer screening. J Med Screen 2001;8:137-44.

25. Bisson B. Methane gas explosion during colonoscopy. Gastroenterol Nurs 1997;20:136-7.

26. Bond JH, Levitt MD. Colonic gas explosion - is a fire extinguisher necessary? Gastroenterology 1979;77:1349-50.

27. Monahan DW, Peluso FE, Goldner F. Combustible colonic gas levels during flexible sigmoidoscopy and colonoscopy. Gastrointest Endosc 1992;38:40-3.

28. Ben Soussan E, Mathieu N, Roque I, Antonietti M. Bowel explosion with colonic perforation during argon plasma coagulation for hemorrhagic radiation-induced proctitis. Gastrointest Endosc 2003;57:412-3.

29. Taylor EW, Keighley MR. Fatal colonic explosion. Gastroenterology 1980;79:178.

30. Ashley OS, Nadel M, Ransohoff DF. Achieving quality in flexible sigmoidoscopy screening for colorectal cancer. Am J Med 2001;111:643-53.

31. Horton K, Reffel A, Rosen K, Farraye FA. Training of nurse practitioners and physician assistants to perform screening flexible sigmoidoscopy. J Am Acad Nurse Pract 2001;13:455-9.

32. ASGE Guidelines for clinical application. Statement on role of short courses in endoscopic training. American Society for Gastrointestinal Endoscopy. Gastrointest Endosc 1999;50:913-4.

33. Datta V, Mandalia M, Mackay S, Darzi A. The PreOp flexible sigmoidoscopy trainer. Validation and early evaluation of a virtual reality based system. Surg Endosc 2002;16:1459-63.

34. Gerson LB, Van Dam J. A prospective randomized trial comparing a virtual reality simulator to bedside teaching for training in sigmoidoscopy. Endoscopy 2003;35:569-75. (Erratum in 2004;36:185).

35. Maule WF. Screening for colorectal cancer by nurse endoscopists. N Engl J Med 1994;330:183-7.

36. Spencer RJ, Ready RL. Utilization of nurse endoscopists for sigmoidoscopic examinations. Dis Colon Rectum 1977;20:94-6. 
37. Palitz AM, Selby JV, Grossman S, et al. The Colon Cancer Prevention Program (CoCaP): Rationale, implementation, and preliminary results. HMO Pract 1997;11:5-12.

38. Schoenfeld P, Lipscomb S, Crook J, et al. Accuracy of polyp detection by gastroenterologists and nurse endoscopists during flexible sigmoidoscopy: A randomized trial. Gastroenterology 1999;117:312-8.

39. Schoenfeld PS, Cash B, Kita J, Piorkowski M, Cruess D, Ransohoff D. Effectiveness and patient satisfaction with screening flexible sigmoidoscopy performed by registered nurses. Gastrointest Endosc 1999;49:158-62.
40. Wallace MB, Kemp JA, Meyer F, et al. Screening for colorectal cancer with flexible sigmoidoscopy by nonphysician endoscopists. Am J Med 1999:107:214-8.

41. DiSario JA, Sanowski RA. Sigmoidoscopy training for nurses and resident physicians. Gastrointest Endosc 1993;39:29-32.

42. Schroy PC, Wiggins T, Winawer SJ, Diaz B, Lightdale CJ. Video endoscopy by nurse practitioners: A model for colorectal cancer screening. Gastrointest Endosc 1988;34:390-4.

43. Adams C, Cardwell C, Cook C, Edwards R, Atkin WS, Morton DG. Effect of hysterectomy status on polyp detection rates at screening flexible sigmoidoscopy. Gastrointest Endosc 2003;57:848-53. 


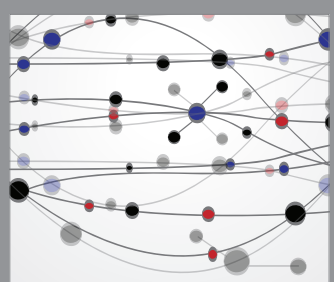

The Scientific World Journal
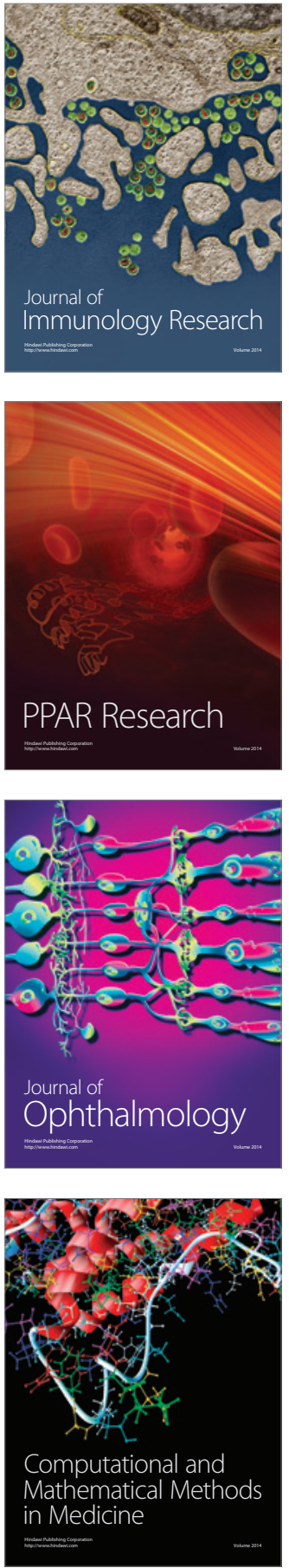

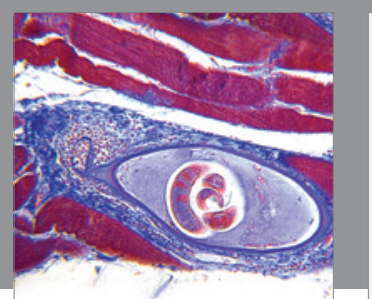

Gastroenterology Research and Practice

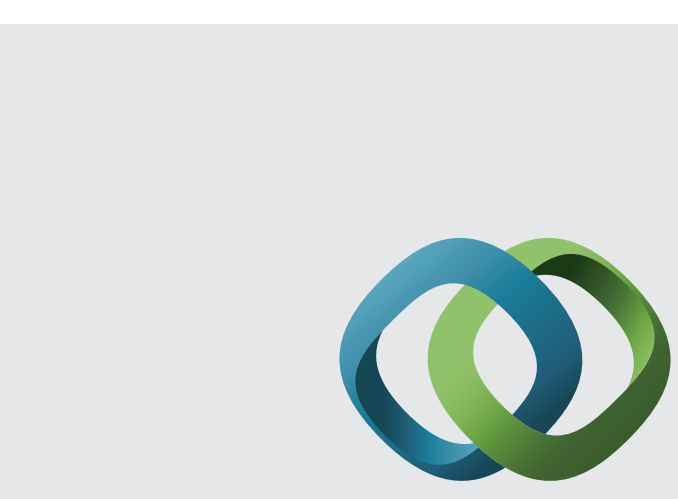

\section{Hindawi}

Submit your manuscripts at

http://www.hindawi.com
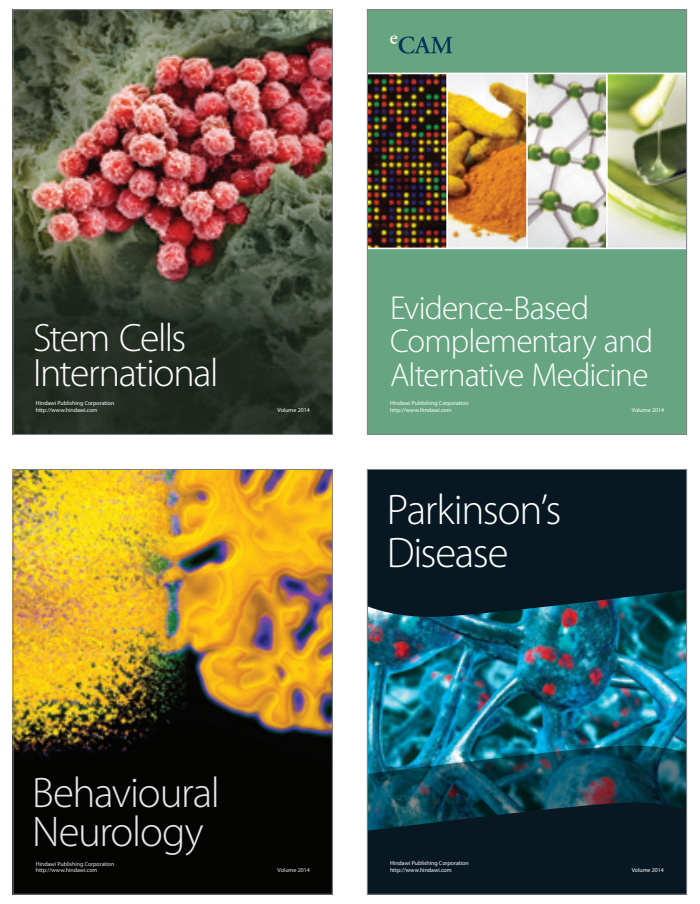
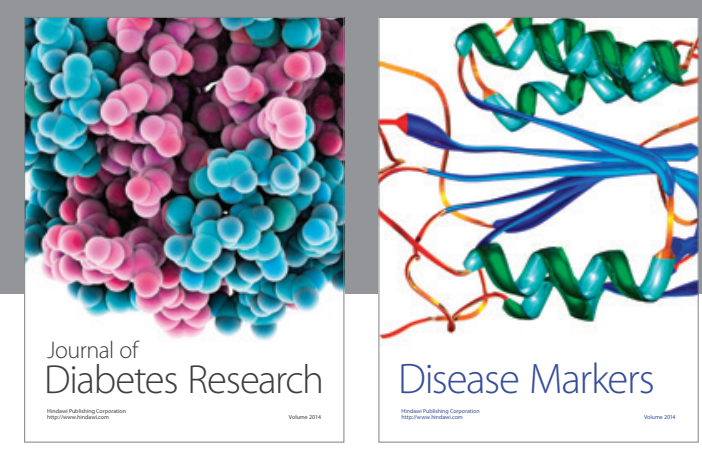

Disease Markers
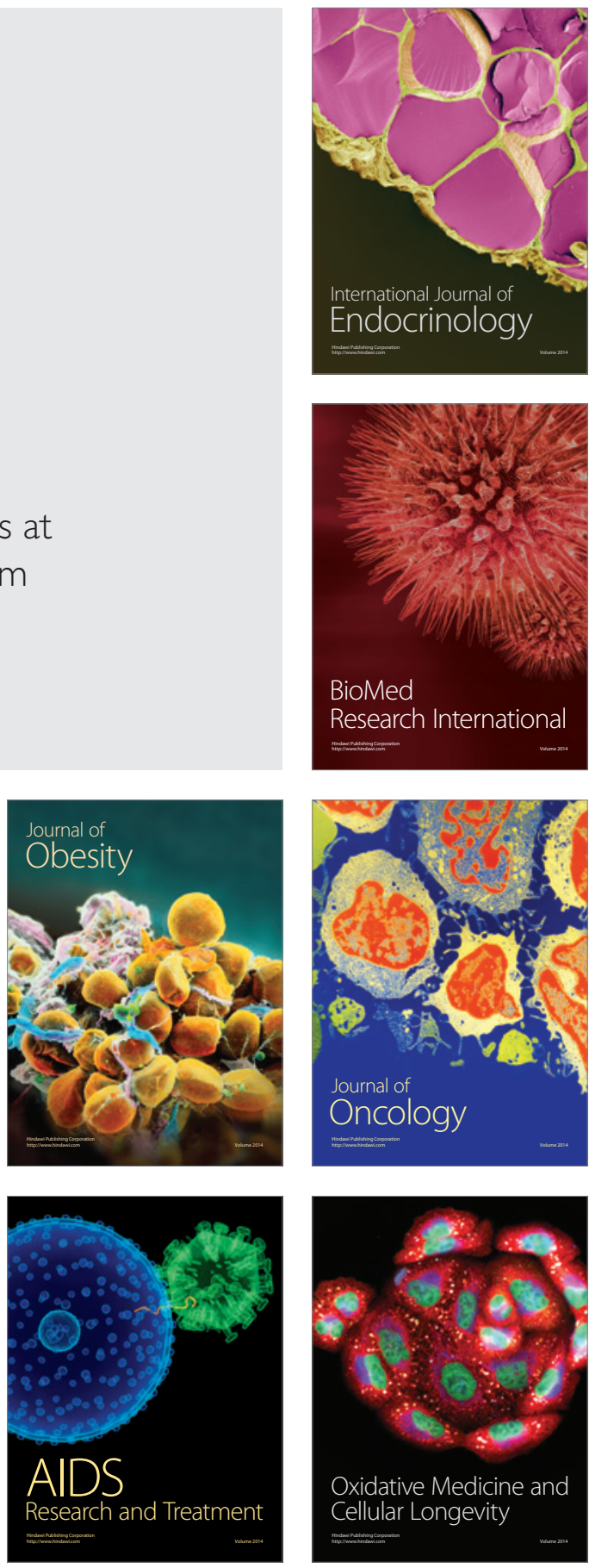